\title{
OPINION
}

\section{Recommendations for Early Diagnosis of Chronic Kidney Disease}

\author{
I. B. Bosan \\ Department of Medicine, Ahmadu Bello University Teaching Hospital, Zaria, Nigeria \\ Reprint requests to: Dr. I. Bosan, Nephrology Unit, Department of Medicine, Ahmadu Bello University \\ Teaching Hospital, Zaria, Nigeria
}

\begin{abstract}
Background: Chronic kidney disease is an important component of chronic non - communicable diseases that are now of pandemic proportions and are the major cause of morbidity and mortality worldwide. Patients with reduced renal function represent a population not only at risk for progression of kidney disease and development of end stage renal disease (ESRD), but also at a greater risk of cardiovascular disease and mortality. Unfortunately, chronic kidney disease is under diagnosed and undetected resulting in lost opportunities for improving the clinical outcome. Early diagnosis with appropriate interventions will improve the quality of care of patients and prevent or delay progression to end stage renal disease. Our objective is to review existing recommendations and examine their adaptation to improving the quality of care for patients with chronic kidney disease in our environment.

Method: Hand searches of published articles and electronic data were the primary sources. Only articles published in the English language were consulted excluding case reports, letters and conference abstracts. Articles of original data were searched from 1980 while review articles and expert committee reports were from 2000.

Results: Early diagnosis of chronic kidney disease is crucial to improving the clinical outcome and reducing the incidence of end stage renal disease. Certain individuals with specific socio demographic and clinical factors are at increased risk of chronic renal disease. All individuals should be assessed as part of routine health encounter, to determine whether they are at increased risk of developing chronic kidney disease based on clinical and socio demographic factors. Individuals at increased risk of developing chronic kidney disease should undergo testing for markers of kidney damage, and to estimate the level of GFR. Individuals found to have chronic kidney disease should be evaluated and treated appropriately. A clinical action plan should be developed for each patient based on the type and stage of renal disease, co-morbid conditions, complications of the disease and risk factors for progression of renal disease or development of cardiovascular disease.

Conclusion: Individuals at increased risk, but found not to have chronic kidney disease, should be advised to follow of risk factor reduction, if appropriate, and undergo repeat periodic evaluation.
\end{abstract}

Key words: Chronic kidney disease, risk factors, screening, early diagnosis, prevention

\begin{abstract}
Résumé
Introduction: Maladie du rein chronique est un composant important des maladies chroniques non transmissibles qui sont actuellement d'une proportion pandémique et sont des causes majeur de la morbidité et mortalité dans le monde entier. Des patients atteints des fonctions d'une diminution rénale constitue une poplation pas seulement à risque pour une progression de la maladie du rein et du dévelopment de la maladie rénale de la dernière étape (MRDE) mais aussi à un plus grand risque de la maladie cardiovasculaire et mortalité. Malheuresement, la maladie du rein chronique est sous diagnostiquée et sans détecter ce qui mène à la perte des occasions d'améliorer le résultat clinique. Un diagnostique précoce avec des interventions adéquates vont améliorer la qualité des soins pour des patients et éviter une progression tardive pour la maladie rénale de la dernière étape. L'objet de cette étude est de faire une rétrospective des récommendations actuelles et étudier leur adaptation pour pouvoir améliorer la qualité des soins pour des patients atteints de la maladie du rein dans notre milieu.

Méthodes: Recherches des articles publiées et des données électroniques sont des sources de base. Des articles publiées en anglais ont été consultées sans compter des rapports des cas, lettres et des résumés de
\end{abstract}


la conférence. Des articles des données originales ont été cherchées de 1980 tandis que bilan des articles et des rapports du comité des spécialistes étaient de l'an 2000.

Résultats: Diagnostique précoce pour la maladie du rein chronique est très important afin d'améliorer le résultat clinique et de réduire la fréquence de la maladie rénale de la dernière étaple. Certains individus avec des facteurs clniniques et socio-démographiques spécifiques ont une augmentation du risque de la maladie du rein chronique. Tout le monde devrait être examiner comme étant la démarche de la routine sanitaire, pour pouvoir décider s'ils sont à un augmentation de risque d'atteindre la maladie chronique de rein base sur des facteurs cliniques et socio-démographiques Des individus qui sont à risque d'atteindre la maladie du rein chronique devraient suivre un test qui va indiquer le dégats du rein, et déterminer le niveau du GFR. Des individus trouvés d'être atteint de la maladie du rein chronique devraient être étudiés et traités convenablement. On devrait établir un plan d'action clinique pour chaque patient d'après le type d'étape de la maladie rénale, conditions co-morbide, complication de la maladie et des facteurs de risque pour progression de la maladie rénale ou développement de la maladie cardiovasculaire.

Conclusion: Des individus avec augmentation, mais trouvés de ne pas atteindre de la maladie du rein chronique, devraient être conseillés de suivre une réduction du facteur du risque, si c'est nécéssaire, suivre une évaluation périodique répétée.

Mots-clés: Maladie du rein chroniqu, facteurs du risque, test du dépistage, diagnostique précoce, prévention

\section{Introduction}

Chronic non-communicable diseases are now of pandemic proportions and are the major cause of morbidity and mortality worldwide. Chronic kidney disease (CKD), diabetes mellitus, hypertension and cardiovascular disease all contribute to the burden of chronic diseases which are replacing acute and communicable diseases as the dominant public health problem even in the developing world. ${ }^{1-4}$ These diseases appear to have an unholy alliance increasing morbidity and mortality and are expected to increase rapidly in the next two decades.

Chronic kidney disease plays a central role and represents a key element within the network of major chronic diseases. For instance, chronic kidney disease is a major risk factor for cardiovascular morbidity and mortality and is also a major complication of diabetes mellitus and hypertension. ${ }^{5}$ Patients with reduced renal function represent a population not only at risk for progression of kidney disease and development of end stage renal disease (ESRD), but also at a greater risk of cardiovascular disease and mortality. Unfortunately, chronic kidney disease is under diagnosed and undetected resulting in lost opportunities for prevention. ${ }^{6}$ There is paucity of programs for detection, management and prevention of chronic kidney disease globally.

Chronic kidney disease has a prolonged latent period during which the disease is present but asymptomatic with progressive renal damage. There is wide variability in the rate of progression among individuals even when similar risk factors are present. 7 This suggests the existence of biologically relevant characteristics that influence the occurrence and course of renal disease. This position is clearly illustrated among individuals with autosomal dominant polycystic kidney disease (ADPKD). Family members who inherit the same mutation of the polycystic gene may demonstrate highly variable rate of progression to end stage renal disease.
Combinations of several factors that result in rapid progression to end stage renal disease define the course of the disease. ${ }^{7,8}$ Some of these factors may be causal while others may be associated with but enhance other factors. ${ }^{7,9}$ Some of these factors are modifiable while others are not. Early diagnosis with appropriate interventions will improve the quality of care of patients and prevent or delay progression to end stage renal disease. ${ }^{8}$

\section{Objective}

The objective is to review existing expert recommendations and examine their adaptation for improving the quality of care and outcomes of individuals with chronic kidney disease in a poor economic environment.

\section{Method}

Hand searches of published literature and searches of electronic data bases were the primary sources. Full journal articles of original data, review articles, metaanalysis and editorials were considered. Case reports, letters and abstracts were excluded. No systematic process was followed to obtain the articles. Only articles published in English language were included in the search. Articles of original data were searched from 1980 while review articles and expert committee reports were searched from 2000 .

\section{Definition and Classification of Chronic Kidney Disease}

Chronic kidney disease is defined either as kidney damage, evidenced by structural or functional abnormalities, for not less than 3 months or a persistent decline in glomerular filtration rate (GFR) to less than $60 \mathrm{ml} / \mathrm{min} / 1.73 \mathrm{~m}^{2}$ for not less than 3 months (Table 1). This definition has provided a basis for the development of the kidney disease outcome quality initiative (K/DOQI) clinical practice 
guidelines for chronic kidney disease evaluation, classification and stratification. ${ }^{10}$ Chronic kidney disease is now uniformly defined ${ }^{11}$ and risk factors for initiation and progression identified (Tables 2, 3). Risk factors are also classified based on response to appropriate intervention programmes and used in cardiovascular disease epidemiology ${ }^{10}$ (Table 4).
Chronic kidney disease can be diagnosed early by evaluating individuals with risk factors for initiation and/or progression of kidney disease 12, 13 and instituting appropriate interventions could either, reverse the disease process, stop or slow down the progression of disease. ${ }^{14}$

Table 1: Definition of chronic kidney disease

a. Kidney damage for not less than three months, defined by structural or functional abnormalities of the kidney with or without decrease in GFR, manifested by either:

Pathological abnormalities, or

Markers of kidney damage including abnormalities in composition of blood, urine or imaging tests

b. GFR less than $60 \mathrm{mls} / \mathrm{min} . / 1.73 \mathrm{~m}^{2}$ for not less than three months with or without kidney damage GFR: Glomerular filtration rate

Table 2: Stages of chronic kidney disease

\begin{tabular}{lll}
\hline Stage & Description & GFR $\left(\mathrm{mls} / \mathrm{min} . / 1.73 \mathrm{~m}^{2}\right.$ \\
\hline 1 & Kidney damage with normal or increased GFR & 90 or more \\
2 & Kidney damage with mild decreased GFR & $60-89$ \\
3 & Moderate decrease in GFR & $30-59$ \\
4 & Severe decrease in GFR & $15-29$ \\
5 & Kidney failure & Less than 15 or requires dialysis \\
\hline
\end{tabular}

Table 3: Potential risk factors for susceptibility to and the initiation of chronic kidney disease

\begin{tabular}{ll}
\hline Hypertension & Renal stones \\
Diabetes & Autoimmune disease \\
Age $>60$ years & Smoking \\
Recovery from acute renal failure & Illicit drugs use \\
Male gender & Neoplasm \\
Low birth weight & Reduced renal mass \\
Low socio economic status & Access to health care facility \\
Recurrent or chronic urinary tract infection & Oxidative stress/carbonyl stress \\
Systemic infections & Insulin resistance syndrome \\
Obstructive uropathy & Hyperlipidaemia \\
Obesity & Proteinuria \\
Familial aggregation & Genetic markers \\
Lead and other heavy metals & Poverty \\
Analgesic abuse & \\
Dietary phytooestrogens & \\
\hline
\end{tabular}

Table 4: Classification of risk factors based on response to interventions

\begin{tabular}{ll}
\hline Classification & Risk factor group \\
\hline Category I & Factors for which interventions have been proven to lower risk \\
Category II & Factors for which interventions are likely to lower risk \\
Category III & Factors for which modification may lower risk \\
Category IV & Factors for which interventions have been proven to lower risk \\
\hline
\end{tabular}

\section{Early Diagnosis of Chronic Kidney Disease}

The K/DOQI clinical practice guidelines for chronic kidney disease evaluation, classification and stratification, recognize individuals with certain clinical and socio demographic characteristics to have increased risk of developing chronic kidney disease. ${ }^{10}$ In guideline 3 of the clinical practice guidelines, 10 some individuals without kidney damage and with normal or elevated GFR are recognized to be at 
increased risk for developing chronic kidney disease and recommend as follows:

a. All individuals should be assessed as part of routine health encounter to determine whether they are at increased risk of developing chronic kidney disease based on clinical and socio demographic factors.

b. Individuals at increased risk of developing chronic kidney disease should undergo testing for markers of kidney damage, and to estimate GFR.

c. Individuals found to have chronic kidney disease should be evaluated and treated as specified in guideline 2.

Evaluate to determine:

i. Diagnosis (type of disease) ii. Comorbid conditions

iii. Severity of kidney disease

iv. Complications

v. Risk of disease progression

vi. Risk of cardiovascular disease

A clinical action plan should be developed for each patient based on the type and stage of renal disease, comorbid conditions, complications of the disease and risk factors for progression of renal disease or development of cardiovascular disease.

d. Individuals at increased risk, but found not to have chronic kidney disease, should be advised to follow of risk factor reduction, if appropriate, and undergo repeat periodic evaluation.

Table 5: Recommended steps in screening for chronic kidney disease

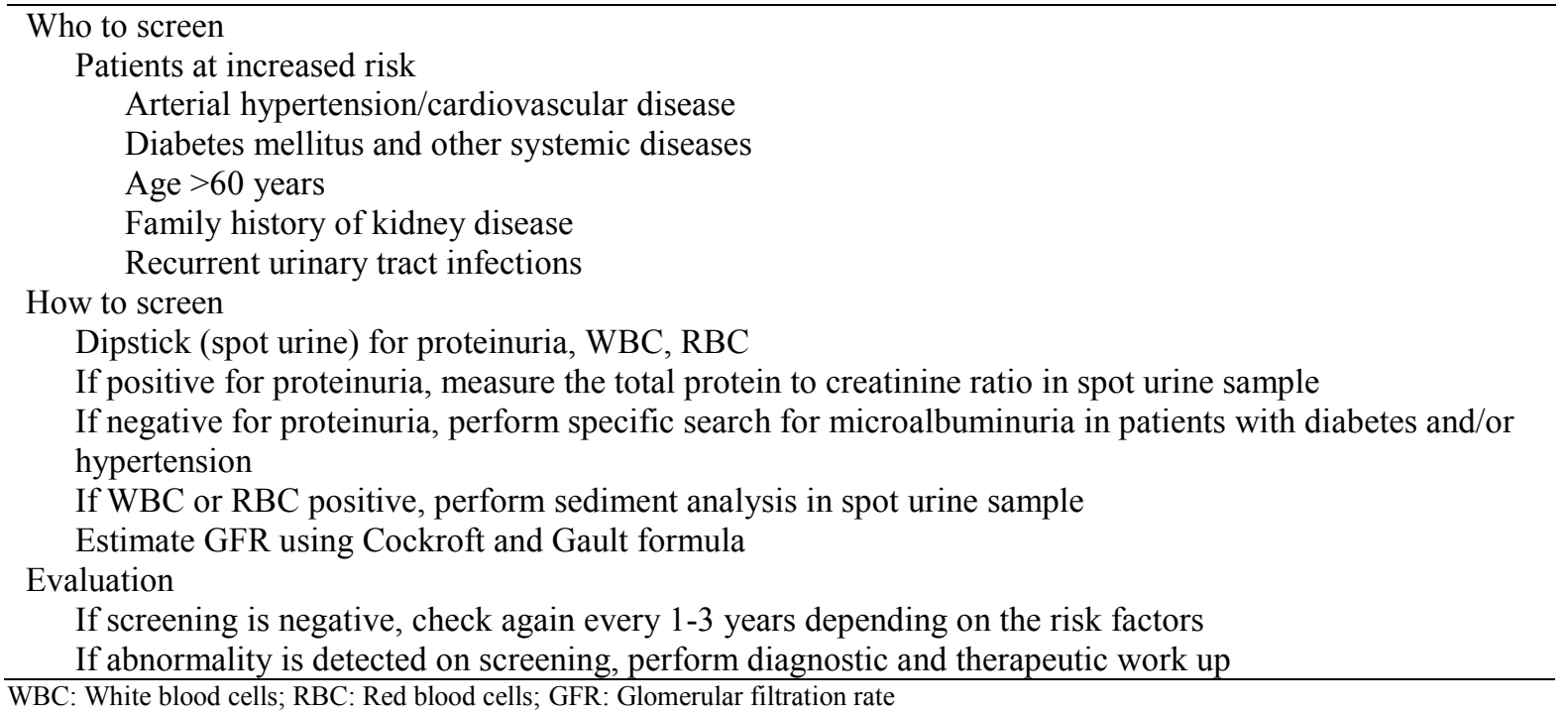

Table 6: Specific equations for estimating glomerular filtration rate

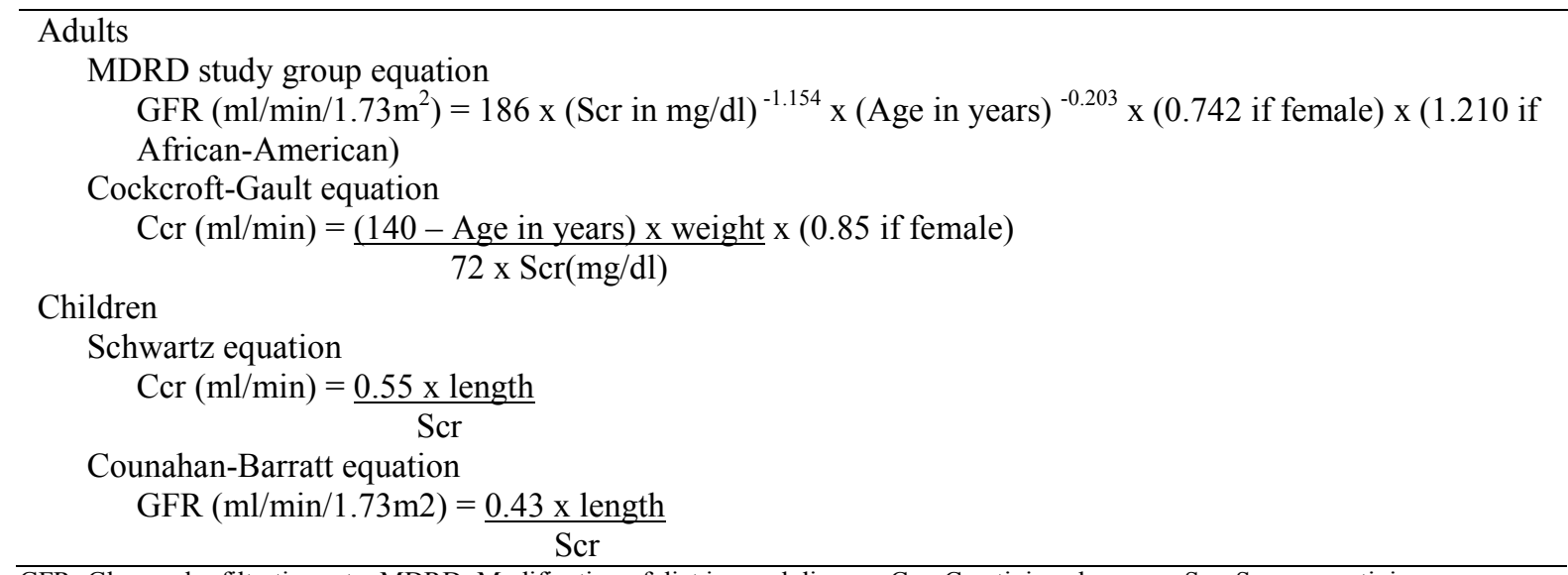

GFR: Glomerular filtration rate; MDRD: Modification of diet in renal disease; Ccr: Creatinine clearance; Scr: Serum creatinine

\section{Screening for Chronic Kidney Disease}

Chronic kidney disease (CKD) detected early can be managed to prevent or slow down the rate of progression to ESRD. ${ }^{8,10,12}$ Failure to recognize
CKD early is a missed opportunity to improve patient outcome. While blood pressure is checked at almost every visit to the doctor, dipstick urinalysis is seldom considered even though it is cheap, available even in the rural areas and very valuable. 
Whole population based programs to promote screening for CKD should increase the rate that persons with previously undetected renal injury are identified and linked to further evaluation and disease modifying interventions. $7,8,10$ Whole population surveys provide an opportunity for health education and counseling by health care providers to promote awareness about the risk of CKD and the benefits of early diagnosis and treatment. Despite the appeal and potential benefits of whole population based screening programs, it is clear from cost effective analysis that high risk population screening is more practicable, more cost effective and more readily acceptable to policy makers. ${ }^{9}$

The international society of nephrology (ISN) consensus workshop on the prevention of progression of renal disease held in Hong Kong in June 2004 came out with a consensus on screening for chronic kidney disease; who to screen, how to screen and how to evaluate the result (Table 5).

Persons with increased risk of developing chronic kidney disease should be tested for markers of kidney damage and estimate the GFR. A risk factor is an attribute that is associated with increased risk of an outcome. The relationship may be causal, determining the out come or may be non causal. Interventions that reduce exposure to causal factors would improve outcome. Non causal factors are associated with outcome through confounding relationship and intervention to reduce exposure may not necessarily improve outcome.

The risk of occurrence or progression of CKD can be predicted from the existence of certain risk factors (Table 3) and this enables the clinician to identify individuals who may benefit from a limited screening program which is cost effective. Such individuals will benefit from a more closely supervised care and follow up and more intensive disease modifying interventions. Some of the risk factors have been tested in randomized clinical trials and found to be suitable targets for intervention. ${ }^{7,8,10}$

If health care providers integrate the needed CKD screening within the existing health care system, the population at high risk will be identified and targeted for screening and intervention. The K/DOQI guidelines identify certain demographic groups characterized by high incidence or prevalence of CKD as populations that should be targeted for screening and prevention. ${ }^{10}$ The progression of CKD is affected by interplay of multiple risk factors with wide variability in the rate of progression among individuals even when similar risk factors are identified. ${ }^{8,10}$

\section{Who should be screened?}

If everyone were to be screened, hardly will anyone with chronic kidney go undetected. Whole population screening is desirable but not practicable because of logistics and huge financial burden. Representative sampling of the community is recommended for establishing the burden of disease in the community. Screening for chronic kidney disease should be part of routine examination for all persons presenting to any health facility for any kind of service. Special attention should be paid on persons at high risk of chronic kidney disease (Tables 3 and 4) if found negative, should be re screened at regular intervals every one to three years depending on the underlying risk factors.

\section{What to look for}

1. Urine abnormalities

Proteinuria

Dipstick urine test on spot urine sample is a very valuable screening test. It is simple, quick, cheap and easy to perform. ${ }^{15}-18$ Abnormal urinary excretion of albumin is a highly sensitive indicator of glomerular disease. ${ }^{8,10,19,20}$ Normal individuals excrete small amounts of albumin less than $30 \mathrm{mg} /$ day or proteins $80 \pm 24 \mathrm{mg} /$ day. Standard urine dipsticks are acceptable for detecting increased total urine protein while albumin specific dipsticks are acceptable for detecting albuminuria and will detect albumin levels in urine when excretion is $300 \mathrm{mg} / \mathrm{day}$ or more. Excretion between $30 \mathrm{mg}$ and $299 \mathrm{mg}$ /day are detected as microalbuminuria. The dipstick test does not detect paraproteins and is recommended for detecting CKD in adults and post pubertal children because of its high sensitivity as a marker of CKD in hypertension, diabetes and glomerular disease. ${ }^{10}$ These are the three leading causes of CKD in Nigeria. ${ }^{21,22}$

The National Kidney foundation K/DOQI clinical practice guidelines the following for the assessment of proteinuria: ${ }^{10}$

a. Under most circumstances, untimed (spot) urine samples should be used to detect and monitor proteinuria in children and adults.

b. It is usually not necessary to obtain a timed urine collection ( 24 hours or overnight) for these evaluations in either children or adults.

c. First morning specimens are preferred, but random specimens are acceptable if first morning specimens are not available.

d. In most cases, screening with the urine dipsticks is acceptable for detecting proteinuria:

i. Standard urine dipsticks are acceptable for detecting increased total urine protein.

ii. Albumin specific dipsticks are acceptable for detecting albuminuria

e. Patients with a positive dipstick test $\left(\geq 1^{+}\right)$ should undergo confirmation of proteinuria by a quantitative measurement (protein-tocreatinine ratio or albumin-to-creatinine ratio) within 3 months.

f. Patients with two or more positive quantitative tests temporarily spaced by 1 to 2 weeks should be diagnosed as having persistent proteinuria and undergo further

g. Monitoring proteinuria in patients with chronic kidney disease should be performed using quantitative measurements.

Patients with diabetes and/or hypertension, who 
have negative dipstick test for proteinuria, should be tested for microalbuminuria as it predicts the later occurrence of overt proteinuria and also a marker of increased cardiovascular complications in diabetes and hypertension. ${ }^{10,23-26}$ Orthostatic proteinuria must be excluded especially in children by repeat measurements on first morning specimen if the initial proteinuia was obtained on a random specimen.

2. Other urine abnormalities

The presence of red blood cells and or white blood cells in the urine may indicate renal damage. Microscopic analysis of the urine sediment is recommended in patients with chronic kidney disease and those at increased risk of developing chronic kidney disease. ${ }^{10}$ A significant number of cellular casts highly suggest significant renal damage.

Imaging studies of the kidney should be performed in patients with chronic kidney disease and those at increased risk of developing the disease.

\section{Estimate glomerular filtration rate}

The glomerular filtration rate should be the parameter used to evaluate the level of kidney function because it is the best overall index of renal function. 10, 27-28 This should be estimated from prediction equations that take into account serum creatinine concentration and some or all of the following variables: age, gender, race and body size. ${ }^{29-31}$ The following equations provide useful estimates of GFR (Table 6):

i. The MDRD (Modification of diet in renal disease) study group and Cockroft-Gault equations for adults

ii. Schwartz and Counahan-Barratt equations for children

The Cockroft-Gault equation estimates the creatinine clearance which over estimates GFR in the obese, however it is a simple useful tool in estimating the level of renal function and very valuable in adjusting drug dosages. ${ }^{29-32}$ It has been validated in adult Africans and shown to be reliable in screening for CKD in the African adults. ${ }^{33-34}$ The MDRD study equation estimates the glomerular filtration rate more accurately and reflects the level of renal function better especially in the obese and those with glomerular filtration rate less than $90 \mathrm{mls} / \mathrm{min},{ }^{30}$ but it is more cumbersome to calculate. The prediction equations are less reliable in screening for CKD in the African children ${ }^{35}$ and should be applied with caution while more reliable methods are being sought. The serum creatinine alone should not be used to assess the level of renal function because it is affected by factors such as the muscle mass of the individual, diet, secretion, generation and extra renal excretion. ${ }^{36-38}$

\section{References}

1. Harris MI, Flegal KM, Cowie CC, Elerhardt MS, Goldstein DE, Little RR. Prevalence of diabetes impaired fasting glucose and impaired glucose tolerance in US adults. The third national health and nutrition examination survey 1988-1994. Diabetes Care 1998; 21:518-524
2. Burt VL, Whelton P, Rocella EJ, Brown C, Cutter JA, Higgins $M$. Prevalence of hypertension in US adult population. Result from the third national health and nutrition examination survey 1988-1994. Hypertension 1995; 25:305-313

3. Chobanian AV, Bakris GL, Black HR, Cushman WC, Green LA, Izzo JL. The seventh report of the joint national committee on prevention, detection, evaluation and treatment of high blood pressure. JNC VII report. JAMA 2003; 289:25602571

4. United States renal data system. Excerpts from the 2000 U.S. renal data system. Annual data report: atlas of end stage renal disease in the United States. Am J Kidney Dis 2000; 36:S1S279

5. Weiner DE, Tighiouart $\mathrm{H}$, Amin $\mathrm{MG}$, et al. Chronic Kidney disease as a risk factor for cardiovascular disease and all-cause mortality: a pooled analysis of community based studies. J Am Soc Nephrol 2004; 15:1307-1315

6. Levey AS, Coresh J, Balk E, et al. National kidney foundation practice guidelines for chronic kidney disease; evaluation, classification and stratification. Ann Intern Med 2003;139: 137-147

7. McClellan WM, Flanders WD. Risk factors for progression of chronic kidney disease. J Am Soc Nephrol 2003; 14:S65-S70

8. Rossert JA, Wauters J-P. Recommendations for screening and management of patients with chronic kidney disease. Nephrol Dial Transplant 2002; 17(suppl 1):19-28

9. McClellan W, Ramirez SPV, Jurkovitz C. Screening for chronic kidney disease: unresolved issues. J Am Soc Nephrol 2003; 14: S81-S87

10. National kidney foundation (NKF) K/DOQI clinical practice guidelines for chronic kidney disease; evaluation, classification, and stratification. Kidney disease outcome initiative. Am J Kidney Dis 2002; 39: S1-S246

11. Hsu CY, Chertow GM. Chronic renal confusion: insufficiency, failure, dysfunction or disease. Am J Kidney Dis 2000; 36:415-418

12. Bosan IB. Chronic kidney disease in Nigeria: primary care physicians must intervene earlier. Nigerian Medical Practitioner 2006; 49: 18-23

13. Hsu CY, Chertow GM, Gurhan GC. Methodological issues in studying the epidemiology of mild to moderate chronic renal insufficiency. Kidney Int 2002; 61: 1567-1576

14. Nisienson AR, Collins AJ, Hurley J, Petersen H, Periera BJ, Steinberg EP. Opportunities for improving the care of patients with chronic renal insufficiency. Current practice patterns. J Am Soc Nephrol 2001; 12:1713-1720

15. Zelmanovitz T, Gross JL, Oliveira JR, Paggi A, Tatsch M, Azevedo MJ. The receiver operating characteristics curve in the evaluation of random urine specimen as a screening test for diabetic nephropathy. Diabetic Care 1997; 20:516-519

16. Schwab SJ, Christensen RL, Dougharty K, Klahr S. Quantitation of proteinuria by use of protein 
to creatinine ratio in single urine samples. Arch Intern Med 1987; 147:943-944

17. Ginsberg JM, Chang BS, Matarese RA, Garella S. Use of ingle voided urine samples to estimate quantitative proteinuria. N Engl J Med 1983; 309:1543-1546

18. Nathan DM, Rosenbaum C, Protasowicki VD. Single void urine samples can be used to estimate quantitative microalbuminuria. Diabetes Care 1987; 10: 414-418

19. Keane WF, Eknoyan G. Proteinuria, albuminuria, risk assessment, detection, elimination (PARADE): position paper of the national kidney foundation. Am J Kidney Dis 1999; 33:10041010

20. Ruggeneti P, Gaspari F, Perna A, Remuzzi G. Cross-sectional longitudinal study of spot morning urine protein/creatinine ratio, 24 hours urine protein excretion rate, glomerular filtration rate and end stage renal failure in chronic renal disease without diabetes. BMJ 1998; 316:504509

21. Adelakun TA, Akinsola A. Hypertension induced renal failure, clinical features, management and prognosis. West Afr Med J 1998; 17:104-108

22. Akinsola A, Odesanmi WO, Ogunniyi JO, Ladipo GOA. Diseases causing renal failure in Nigeria: a prospective study of 100 consecutive cases. Afr J Med med Sci 1989; 18: 131-137

23. Mogensen CE. Microalbuminuria predicts clinical proteinuria and early mortality in maturity onset diabetes. N Engl J Med 1984; 310:356-360

24. Bigazzi R, Bianchi S, Baldari D, Sgherri G, Baldari G, Campese VM. Microalbuminuria in salt sensitive patients. A marker for renal and cardiovascular risk factors. Hypertension 1994; 23:195-199

25. Yudkin JS, Forrest RD, Jackson CA. Microalbuminuria as predictor of vascular disease in non diabetic subjects. Lancet 1998; 2: 530-533

26. Scheid DC, McCarthy LH, Lawler FH, Hamm RM, Reilly KE. Screening for microalbuminuria to prevent nephropathy in patients with diabetes. A systemic review of the evidence. J Fam Pract 2001; 50:661-668

27. Lindeman RD, Robin J, Shock NW. Longitudinal studies on the rate of decline in renal function with age. J Am Geriatr Soc 1985; 33:278-285

28. Manjunath G, Tighiouart H, Coresh J, Macleod B, Salem DN, Griffith JL. Level of kidney function as a risk factor for cardiovascular outcomes in the elderly. Kidney Int 2003; 63:1121-1129

29. Cockroft DW, Gault MH. Prediction of creatinine clearance from serum creatinine. Nephron 1976; 16:31-41

30. Levey AS, Bosch JP, Breyer LJ, Greene T, RogersN, Roth D. A more accurate method to estimate glomerular filtration rate from serum creatinine: a new prediction equation. Ann Intern Med 1999; 130:461-470

31. Levey AS, Green T, Kusek JW, Beck GJ, Group MS. A simplified equation to predict glomerular filtration rate from serum creatinine. J Am Soc Nephrol 2000; 11:0828

32. Cochran M, St. John A. A comparison between estimation of GFR using ${ }^{99}$ TcDTPA clearance and the approximation of Cockroft and Gault. Aust NZ J Med 1993; 23:494-497

33. MCligeyo SO, Shoji T, Hayashi T, Kitamura E. Calculation of creatinine clearance from plasma creatinine. East Afr Med J 1993; 70:3-5

34. Sanusi AA, Akinsola A, Ajayi AA. Creatinine clearance estimation from serum creatinine values: evaluation and comparison of five prediction formulae in Nigerian patients. Afr $\mathrm{J}$ Med med Sci 2000; 29:7-11

35. Gbadegesin RA, Asinobi AO, Osinusi K. Inaccuracy of the Schwartz formula in estimating glomerular filtration in Nigerian children. Ann Trop Paediatr 1997; 17:179-185

36. Perrone RD, Madias NE, Levey AS. Serum creatinine as an index of renal function: new insights into old concepts. Clin Chem 1992; 38:1933-1953

37. Toto RD. Conventional measurements of renal function utilizing serum creatinine, creatinine clearance, inulin and aminohippuric acid clearance. Current Opin Nephrol Hypertension 1995; 4:505-509

38. Shemesh O, Golbetz H, Kriss JP, Myers BD. Limitations of creatinine as a filtration marker in glomerulopathic patients. Kidney Int 1985; 28:830-838 